Primary submission: 03.06.2020 | Final acceptance: 15.09.2020

\title{
The Major Issues Facing Staff in Islamic Banking Industry and its Impact on Productivity
}

Harith Yas ${ }^{1}$, Abbas Mardani ${ }^{1}$, and Ali Alfarttoosi ${ }^{2}$

ABSTRACT

\begin{abstract}
The main concern of the research were the challenges faced by the staff working in the Islamic banking Industry. The study was conducted on Islam based banks between the 5th and 22nd of March 2020 to identify the challenges faced by the staff. Again, the results obtained aided in ascertaining the correlation between the staff challenges and its unique model of operation from conventional banks. Research objectives included generating results that assisted in developing staff skills. Additionally, investigating the nature and increase in sales and implementing methods of attracting customers to the banks were the last objectives of the study. In the methodological part, the quantitative data collection focused on questionnaires, whereas qualitative concentrated on interviews with the aid of descriptive statistics and observation. The sample used was composed of 200 participants. A total number of 8 Islamic banks were engaged in retrieving the necessary information from staff. The findings acquired through the SEM approach confirm that misdemeanor and personal problems have shown their negatively insignificant impact on the productivity of the employees. Whereas, financial rewards contributed to the positive and significant impact on the productivity factor. Banking sector management, specifically in Islamic banks, would greatly benefit from acquainting themselves with the current study's findings to increase the productivity of their employees. However, significant attention is required to control the adverse influence from the miscellaneous factors, and personal problem which are causing lower employee productivity.
\end{abstract}

KEY WORDS: $\quad$ employee's productivity, financial reward, job content, skills, banking industry

JEL Classification: $\mathrm{M} 10, \mathrm{M} 14, \mathrm{M} 40$.

${ }^{1}$ Azman Hashim International Business School, Universiti Teknologi Malaysia, Malaysia

${ }^{2}$ Business School, University Pendidikan Sultan Idris, Malaysia

\section{Introduction}

The Islamic banking industry (IBI) operates differently from other conventional banks, through offering interest-free products. Abdul-Majid et al. (2010) stated that there are various strategies applied in Islamic banks, and they have attracted not only praises but also critiques by the interested observers. The industry has received a considerable number of praise from customers and other parties by transitioning from a mere theory into a banking platform worth two trillion US dollars. Importantly, IBI has attracted several non-Muslim customers because its system tends to be

Correspondence concerning this article should be addressed to: Harith Yas, Azman Hashim International Business School, Universiti Teknologi, Malaysia. E-mail: harith.albayati@yahoo.com less risky, yet stable when compared to conventional banks. It is, however, worth noting that the industry is associated with various challenges, including late payments, unfavorable currency rates, and non-consideration of the poor and small traders (Hassan and Aliyu, 2018). The unique mode of operation has attracted critique, which reveals that the Islamic banking industry has entirely ignored its underlying philosophy for the last few decades. It is, however, worth noting that the challenges have turned out to adversely impact the staff members who are mandated to oversee the operation of Islamic banks.

The Islamic banking staff has been struggling with putting in place effective strategies for creating awareness of its products, a situation that has reduced sales volume performance among the staff. Equally, 
the public does not have a clear view of what Islamic banking entails because the systems do not advocate for prioritizing its products and services (Hassan and Aliyu, 2018). The regulatory regime governing the Islamic banking industry does not allow the staff to harmonize their operations with those of the other banks, there impacting skill development adversely. Precisely, the team finds it challenging to shape their expertise concerning advancing technology due to the limited borrowing of techniques from conventional banks (Bose, 2018b). Notably, Islamic regulators advocates for developing the industry to a higher scaled baking sector as opposed to bringing in more customers and promoting the welfare of the staff. As a consequence, the staff tends to be limited since they cannot boost their sales volume by inviting more customers.

The research was vital in identifying the problems facing the staff working in the Islamic banking industry. Besides, the study contributed significantly to the nature of investigating and strategizing in order to increase sales. Additionally, it is through research that staff acquired methods of attracting customers to the Islamic banking industry. The questions below aided the researcher in covering and understanding the Islamic banking mode of operation and the challenges facing its staff. Can Islamic banking staff members create awareness of bank products to the public? Does the banking system allow for staff skill development through adopting techniques applied in conventional banks? Is the staff allowed to introduce the services offered to other potential customers? How does the Islamic bank thrive in the industry without charging its customers an interest?

\section{Literature Review}

Customer services are vital for the success of any bank. In connection, the Islamic banking industry does not put much emphasis on promoting the services offered to customers (Jan, 2018). The previous research suggests that the Islamic banking industry focuses strictly on Islamic customers and businesses with stable financial income, leaving out non-Muslims and other types of customers. As a result, customers diverge their interest to other institutions that have a well-grounded history in service delivery (Maghyereh, 2018) (Peppard, 2000), the Islamic banking industry is rated among the stable sectors; however, it tends not to be useful in developing the customer's services. Notably, the Islamic banking industry demotes the motivation of its staff since they are limited to the type and level of customers to engage.

The Islamic banking industry tends to be reluctant when it comes to developing staff skills. Furthermore, total quality management is rarely applied, which in turn impacts the level of staff competency adversely. Bose (2018b) suggests that the staff working in a banking environment are required to share their opinions freely when faced with a challenge in a bid to come up with informed decisions (Maghyereh, 2018). The previous research suggests that IBI struggle with maintaining staff key competencies, including management, technical, and humanitarian skills (Hassan and Aliyu, 2018). Notably, the IBI does not factor experience and personal qualities when absorbing staff into the organization.

Islamic Banking institutions (IBI) employ sale staff and other staff just like any functional company, and they implement all means necessary to reach set targets. The sales management team in the Islamic banking industry does not encourage their peers to work towards achieving sales targets (Hassan and Aliyu, 2018). According to Jan (2018), the Islamic banking industry rebuilds the skills of their staffs in sales management but only for the employees with high-income earners. (Saeed, 1996) attests that the IBI is reported to have stagnant, yet stable sales volume, as they do not attract more customers. Overall, the systems are designed in such a way that they only meet the needs, desires, and preferences of high-income earners, a condition that limits staff's engagement with diverse customers.

The IBI has fell short of coming up with new marketing strategies that would attract more nonMuslim customers. The process of attracting and retaining customers is a complex undertaking since it entails providing the best products and services to other institutions. Azmat et al. (2015) reveal that Islamic banking systems have been finding it challenging to attract customers because of the competitive national interest rate, which is induced by the crowded industry. It is, however, worth noting that some customers have lost confidence in investing in the financial institution due to the continuous failures of 
several Islamic banks. (Okumus, 2005) opines that the Islamic banking industry can elevate its market score by engaging in marketing campaigns to encourage non-Muslim customers to take loans and making more deposits. Importantly, Traditional marketing strategies such as networking and communications should also be encouraged while minding conventional tactics.

After reviewing the research relating to Islamic banking, it was evident that researchers have not provided enough critiques on the same (Gerrard and Cunningham, 1997; Hussain et al., 2020). Again, there is not enough research relating to how the Islamic banking industry can utilize management skills to attain better results (Hassan \& Aliyu, 2018). Most of the information provided in the literature review was mainly concerned about the importance of adopting staff skills, increasing sales, and providing the customers in the community with necessary information relating to banking. The information gathered while writing the literature review contributes significantly to the understanding of the modes of operation in the IBI. Additionally, it is through the literature review that the reader can understand the nature of the IBI in the United Arab Emirates (Bose, 2018a). Besides, the Islamic banks can get access to skills they can apply in their projects, and industry-related information to realize improved results.

\section{Methodology}

TThe primary purpose of the methodology was to provide the strategies that were used during data collection and analysis. The research methodology was defined as the discovery and systematic pursuit of knowledge. Kumar et al. (2008) suggested that the research methodology provides a plan for digging deep into a study in an effort to generate concrete results. In this paper, an approach was determined that aided the researcher during the study. The research focused on both quantitative and qualitative data collection. The quantitative part of data collection focused on questionnaires (covering various factors which are directly or indirectly impacting on the productivity of the employees, working in different Islamic banking firms), whereas qualitative concentrated on interviews. Questionnaires were designed to retrieve information about the critical problems experienced by Islamic bank staff members. The questionnaires were formulated in such a way to gather the necessary information from the distribution sample of staff from various Islamic banks. Research objectives were was achieved through conducting research, particularly by collecting technical data with the aid of the questionnaire and interviews. It is through the questionnaires that the researcher got a clear view of the problems facing the staff in the Islamic banking industry. Additionally, the questions provide a direction while designing data collection methods. Staff members from various Islamic banks were interviewed to obtain views towards their challenges. During the interviews, the employees' opinion was recorded to arrive at an overall analysis. Two hundred staff members were interviewed, and the results obtained are representative of the entire staff in the IBI. The participants were encouraged to provide honest answers to aid the study process and to achieve a reliable outcome. The questionnaires used in the process were clear enough to the interviewees in addition to addressing the intended purpose of the research. As a result, the questions asked required short answers such as yes or no. The following set of opinions and questions overruled the interview process. Can Islamic banking staff create awareness of products to the public? Does the banking system allow staff skill development through adopting techniques applied in conventional banks? Are the staff members allowed to introduce the services offered to other potential customers? Research questions were analyzed with the help of an IBI case study. The purpose of the case study was to reveal the challenges faced by the staff operating in the IBI. The case study analyzed obstacles faced by the team while trying to attract more customers to the bank. It is through the case study that the researcher got to know the sales and skill development challenges faced by the Islamic bank staff. Both the participants and interviewees were given questionnaires and the selection was made randomly from 8 Islamic banks. The sample size for the study consisted in 200 respondents from the departments of various Islamic banks. The study was conducted on eight banks in the IBI. For clarity, the current study's analyses are divided into two categories. Firstly, opinions of the respondents against four stated queries were provided through descriptive and percentage scores. Secondly, structural equation modelling (SEM) technique was applied to examine the influence of miscellaneous factors, personal prob- 
lems, job content, manager's attitude, organizational culture, and financial reward on the productivity of the employees in the targeted banking industry.

\section{Study Results I}

The questionnaire was composed of four questions that aided in achieving the goal of research. The group of respondents included 120 males and 80 males, totaling to 200 participants. In the current study, the frequency percentages were presented using statistical tables. A statistical program was used for tabulation, open space classification, and the testing correlation between variables.

Based on Figure 2, it evident that a large number of staff members from the Islamic banking industry (82\%) stress the need to develop staff skills in the bank. Developing skills is vital since only $15 \%$ of the total persons interviewed disagreed with opinion, and 3\% could not assess their views towards the use of technology to shape the competency of staff in a bank.

Figure 3 clearly demonstrates that 87 participants had a strong interest in bringing customers into the banks, 53 were on average status, 13 small, 43 not clear, and four did not know. The above results bring forth an illustration that the IBI does not involve staffs in the process of making decisions and planning processes. Figure 4 shows that $48.5 \%$ of participants had a keen interest in developing the skills of staff in the bank, $32 \%$ were on average status, $7.5 \%$ small, $11.5 \%$ not clear, and $0.5 \%$ did not know. The above results show that half of the staff did not understand the rationale behind the core competency for the success of the Islamic banking industry.

Figure 5 confirmed that $80 \%$ of 200 participants had a strong belief that the services offered to the customers are of much importance. $16.5 \%$ of the participants seemed to agree with the above statement partially, 1.5 did not know, 1\% disagreed, and $1 \%$ strongly disagreed. The results show that the IBI has tried to inform its staff on the benefits accrued from the developmental management of customer service.

The above-presented Figure 6 confirms that the staff members in the Islamic banking industry have a firm idea that sales volume needs to be increased.
Approximately three-quarters of the total population, which is

140 participants strongly agreed that sales required to be boosted, 40 partially agreed, five did not know, 11 disagreed, and 4 had a strong feeling that there was no need for increasing sales.

The results generated in the section confirmed that most of the staff in the Islamic banks has a clear view that the development of skills is vital in an organization. It is worth noting that the Islamic banking industry has been educating its members on skill development, which would aid in achieving their goals and meeting the challenges facing the new Islamic banks (Maghyereh, 2018). The question relating to bringing customers into the Islamic banks did not attract much attention to almost half of the bank's staff. Precisely, only 78 out of 200 participants showed keen interest in encouraging customers to seek financial services from the Islamic banking industry (Tiwari et al., 2006). As a result, the industry needs to put more emphasis on the planning process while cooperating with various departments to bring customers in the Islamic banks, thereby increasing the number of service users.

Figure 4 confirmed that $48 \%$ of staff had a strong feeling that their skills needed to be developed. Therefore, there seems to be no positive relationship between skill development and training as well as high academic performance. Based on the above illustration, it is evident that the Islamic banks have not been putting efforts to improve the performance of staff concerning the technological advancement. The Islamic banking industry staffs have a clear view that the services offered to the customers are vital in developing the activities of the Islamic banking industry. The results confirmed that over $80 \%$ of the staff had a strong feeling that the services offered to the customer are significant in taking the organization to the next level (Bose, 2018b). The Islamic banking industry can boost its service provision through sales promotion, engaging with customers at a personal level, and offering other services that are not provided in other conventional banks. The question on staff suggestion was vital in proving the validity of the previous data that planning is pivotal in boosting the Islamic 


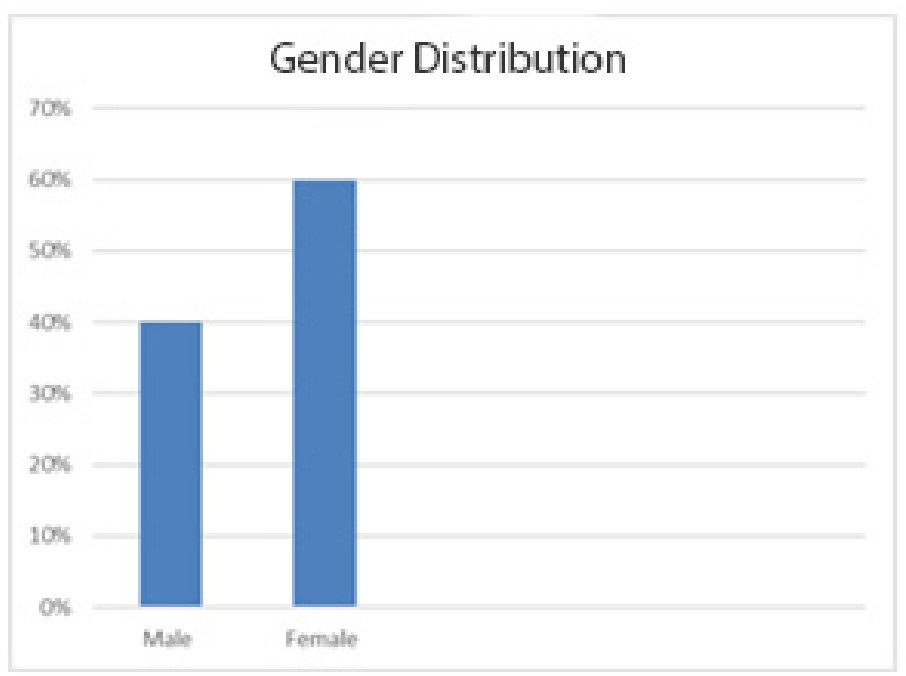

Figure 1. Respondents' distribution.

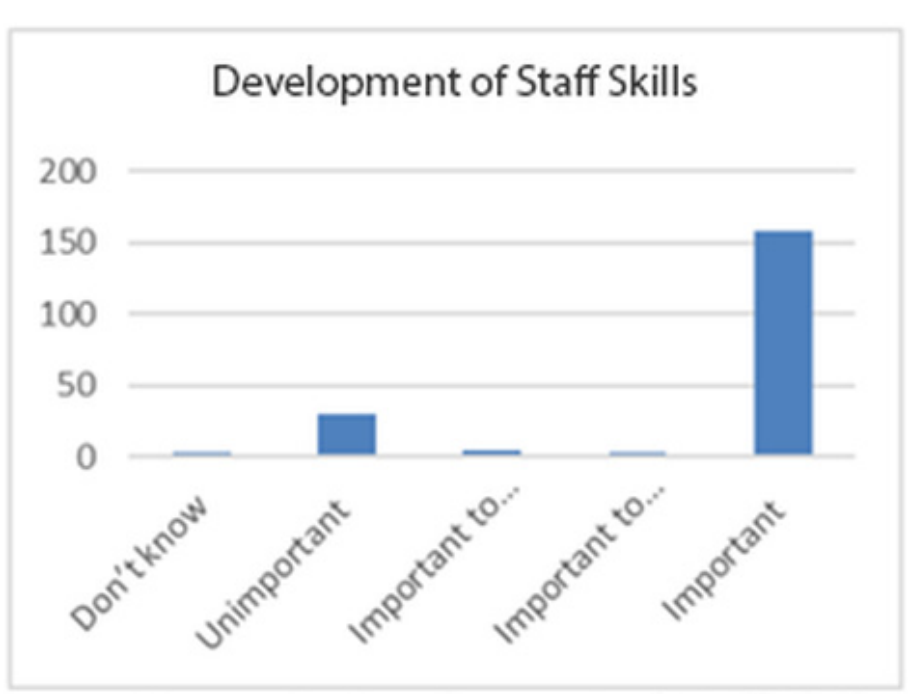

Figure 2. Development of staff skills. 


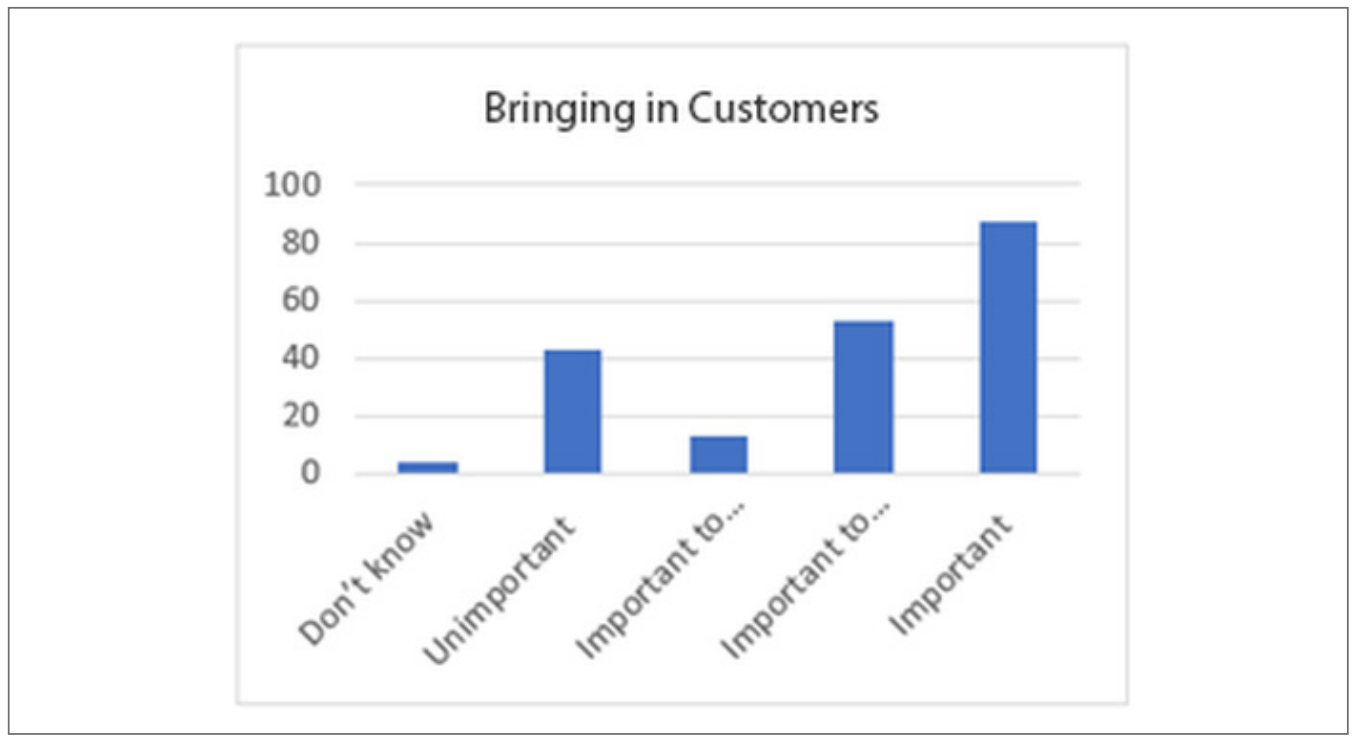

Figure 3. Islamic banks' interest in bringing customers.

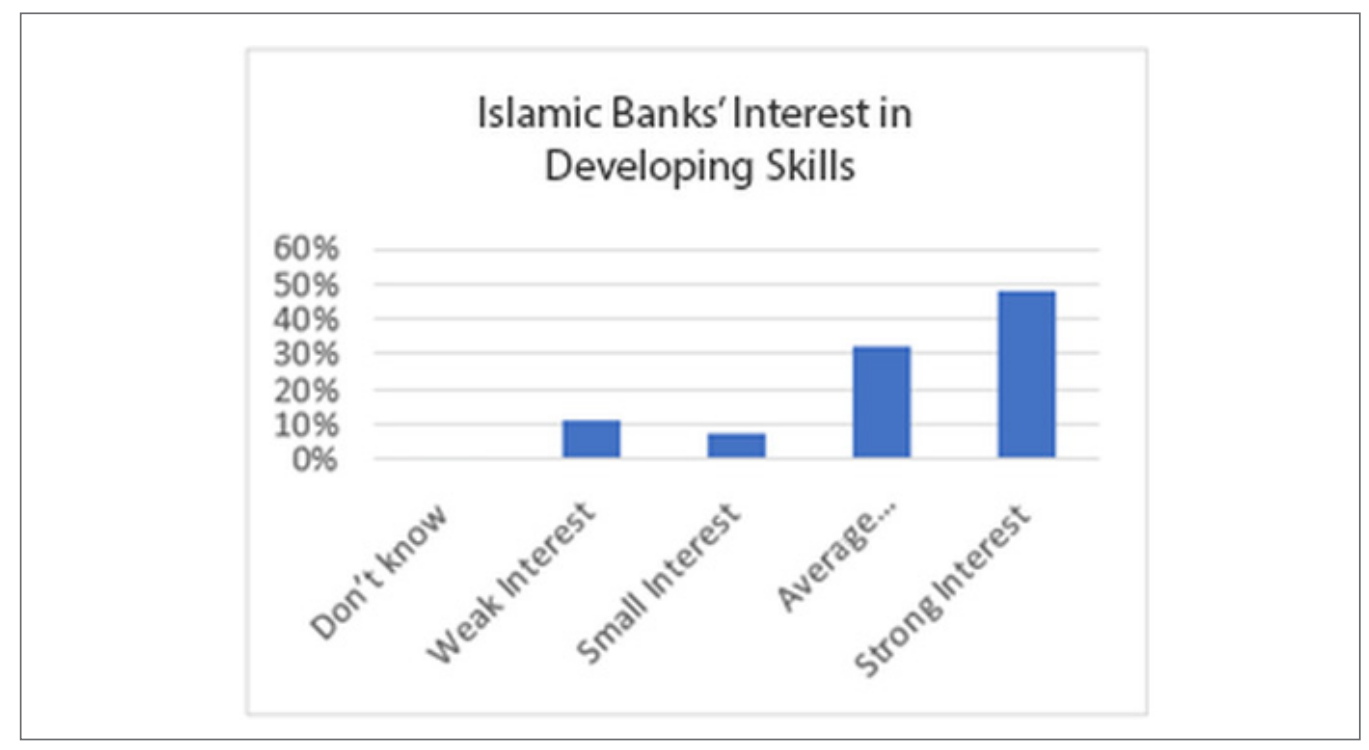

Figure 4. Development of staff skills interest among banks. 


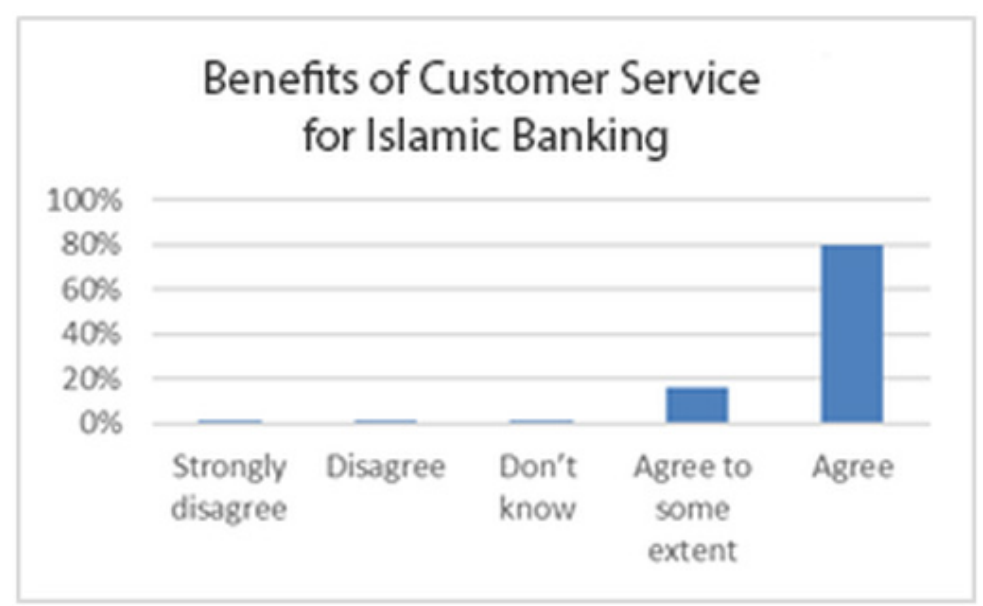

Figure 5. Staff benefits for the bank from customer service.

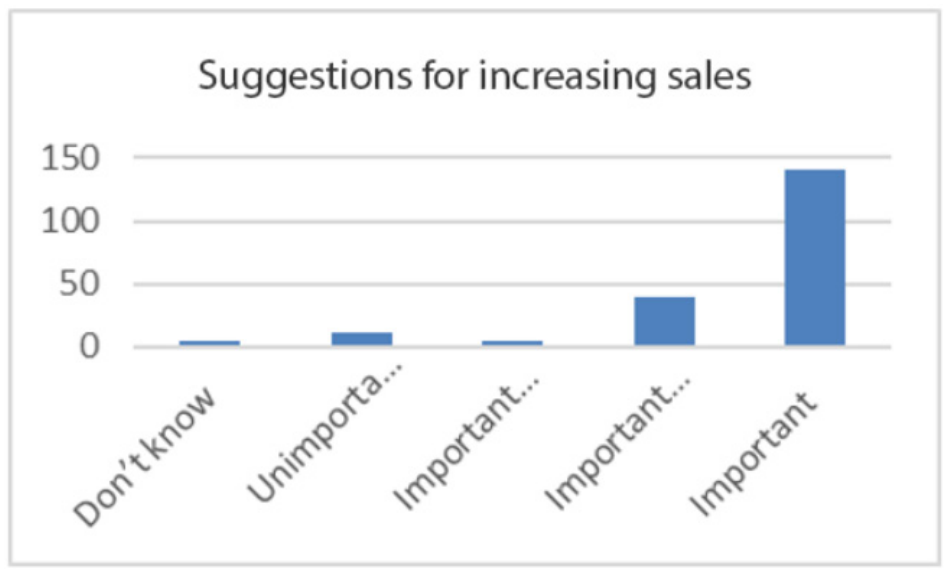

Figure 6. Suggestions for an increase in sales. 
bank's staff skills as well as sales volume. Notably, 140 respondents out of 200 suggested that they would actively support the strategies for increasing sales volume. The Islamic banking industry should get it clear that boosting sales volume is a complex undertaking since it entails effective management of finances, administrative activities, human resources, and general organizational aspects (Hassan and Aliyu, 2018).

\section{Study Results 2}

Our study has divided the key factors affecting the employees' productivity into different categories like miscellaneous, organizational culture, personal problems, manager's attitude, job content and financial reward. As per the mean score for the first four items entitled as miscellaneous items affecting the productivity of the employees, a higher mean score of above 4.45 was observed for the staffing skills, bringing customers, services to customers, and suggestions for the sales. Furthermore, organizational culture is reflected through four items with the relative mean score of $3.47,4.51,3.51$, and 4.50 respectively. It means that there is a higher as well as average means trend in the four items of organizational culture. For the personal problem our study reflects only the PP1 is showing a mean score of below 4 which is 3.50 , where the mean trend for the remaining items was observed as $4.51,4.53,4.47$, and 4.55 . It means that there is a good trend from the sample of 200 respondents including both male and females while providing their valuable responses against five points likert scale.

The factor of personal problem is also measured through five items and their relative mean scores are showing a higher trend, whereas, standard deviation for each of the stated item is relatively low. Meanwhile, MA items representatives the measurement of manager's attitude where mean score is above 4 . It shows that there is a good trend from the respondents while providing their responses over five points likert scale. In addition, both the items for job content and financial rewards are also presented through mean and standard deviation. Lastly, employee's productivity is reflected through RP1 to PR3 with the mean values of $4.50,4.44$, and 4.53 respectively.

After descriptive scores, factor loadings are gener- ated and provided in Table 2. It is observed that miscellaneous items are providing the factor loadings of $.71, .68,69$. and .71 respectively. For organizational culture, factor loadings are .58, .82, .82, and .78. For personal problems, factor loadings are $.82, .71, .63$, .78 , and .69 respectively. Manger's attitude is reflected through the loadings of $.72, .77, .82, .66$, and .62. For job content, it is observed that loadings for the three items are .61, .73, and .72. For financial reward, CFA is providing a score of $.69, .52,69, .82$ and .87 . In the end, productivity items are providing the loading values of $.66, .87$, and .82 .

Figure 7 shows the structural model of our research, covering the Misc. factors, organizational culture, job content, personal problems, manager's attitude, and financial reward as main exogenous constructs with their relative items. For measuring the employees' productivity, three sub items are added and assuming it as main endogenous construct under present study. The single headed arrows in the figure below are presenting the overall impact of selected exogenous variables on the productivity of the employees working in the IBI.

Finally, the findings for the structural model as presented under Figure 7 are provided in Table 3. While going for the discussion of the results, our study has tested the following null and alternative hypotheses.

H0: Productivity of the employees working in Islamic banking sector is not influenced by Miscellaneous factors.

$\mathrm{H}$-a: Productivity of the employees working in Islamic banking sector is significantly influenced by Miscellaneous factors.

H0: Productivity of the employees working in Islamic banking sector is not influenced by personal problems.

H-b: Productivity of the employees working in Islamic banking sector is significantly influenced by personal problems.

H0: Productivity of the employees working in Islamic banking sector is not influenced by organizational culture.

$\mathrm{H}-\mathrm{c}$ : Productivity of the employees working in Islamic banking sector is significantly influenced by organizational culture.

H0: Productivity of the employees working in Is- 
Table 1. Descriptive Statistics

\begin{tabular}{|c|c|c|c|c|c|c|c|}
\hline Variable & Obs & Mean & $\begin{array}{l}\text { Std. } \\
\text { Dev. }\end{array}$ & $\begin{array}{l}\text { Vari- } \\
\text { able }\end{array}$ & Obs & Mean & Std.Dev. \\
\hline STAFFSKILLS & 200 & 4.488 & 0.501 & MA3 & 200 & 4.537 & 0.521 \\
\hline BRINGINGCU S & 200 & 4.493 & 0.501 & MA4 & 200 & 4.478 & 0.501 \\
\hline SERVICESTO S & 200 & 4.537 & 0.552 & MA5 & 200 & 4.498 & 0.501 \\
\hline SUGGESTION S & 200 & 4.458 & 0.499 & $\mathrm{JC} 1$ & 200 & 4.453 & 0.499 \\
\hline $\mathrm{OC} 1$ & 200 & 3.478 & 0.501 & JC2 & 200 & 4.453 & 0.499 \\
\hline OC2 & 200 & 4.517 & 0.501 & JC3 & 200 & 4.493 & 0.501 \\
\hline OC3 & 200 & 3.517 & 0.505 & FR1 & 200 & 4.547 & 0.499 \\
\hline OC4 & 200 & 4.507 & 0.501 & FR2 & 200 & 4.483 & 0.501 \\
\hline PP1 & 200 & 3.507 & 0.506 & FR3 & 200 & 4.547 & 0.499 \\
\hline PP2 & 200 & 4.512 & 0.501 & FR4 & 200 & 4.473 & 0.501 \\
\hline PP3 & 200 & 4.537 & 0.520 & FR5 & 200 & 4.468 & 0.552 \\
\hline PP4 & 200 & 4.473 & 0.520 & PR1 & 200 & 4.507 & 0.501 \\
\hline PP5 & 200 & 4.557 & 0.498 & PR2 & 200 & 4.443 & 0.498 \\
\hline MA1 & 200 & 4.502 & 0.501 & PR3 & 200 & 4.537 & 0.514 \\
\hline & & & \multicolumn{2}{|c|}{ Obs $=200$} & $\mathrm{Me}$ & 4.512 & Std.Dev.0.501 \\
\hline
\end{tabular}

lamic banking sector is not influenced by manager's attitude.

$\mathrm{H}-\mathrm{d}$ : Productivity of the employees working in Islamic banking sector is significantly influenced by manager's attitude.

H0: Productivity of the employees working in Islamic banking sector is not influenced by job contents.

$\mathrm{H}$-e: Productivity of the employees working in Islamic banking sector is significantly influenced by job contents.

H0: Productivity of the employees working in Islamic banking sector is not influenced by financial reward.

$\mathrm{H}$-f: Productivity of the employees working in Islamic banking sector is significantly influenced by financial reward.

The results for the structural model are provided in Table 3. At first, we examined that miscellaneous factors have provided a coefficient of -.151 which re- 
Table 2. Factor Loadings Through CFA

\begin{tabular}{|c|c|}
\hline VARIABLE & FACTOR LOADINGS \\
\hline STAFFSKILLS & 0.712 \\
\hline BRINGINGCU S & 0.687 \\
\hline SERVICESTO S & 0.698 \\
\hline SUGGESTION S & 0.718 \\
\hline OC1 & 0.581 \\
\hline OC2 & 0.821 \\
\hline OC3 & 0.827 \\
\hline OC4 & 0.783 \\
\hline PP1 & 0.827 \\
\hline PP2 & 0.716 \\
\hline PP3 & 0.639 \\
\hline PP4 & 0.782 \\
\hline PP5 & 0.698 \\
\hline MA1 & 0.728 \\
\hline MA2 & 0.772 \\
\hline MA3 & 0.828 \\
\hline MA4 & 0.662 \\
\hline MA5 & 0.628 \\
\hline $\mathrm{JC} 1$ & 0.619 \\
\hline JC2 & 0.737 \\
\hline JC3 & 0.729 \\
\hline FR1 & 0.697 \\
\hline
\end{tabular}

FR1 
Table 2. Factor Loadings Through CFA (Continued)

\begin{tabular}{lc}
\hline VARIABLE & FACTOR LOADINGS \\
\hline FR2 & 0.528 \\
FR3 & 0.692 \\
FR4 & 0.827 \\
FR5 & 0.874 \\
PR1 & \\
PR2 & 0.669 \\
PR3 & 0.874
\end{tabular}

flects their overall negative impact on the employees' productivity in the Islamic banking industry. This would show that for every unit increase in the miscellaneous factors, there is an adverse impact on the productivity factor. This coefficient has also shown a standard error of 0.071 and critical ration of -2.12 . Finally, based on this critical ration p-value of 0.035 was achieved which is significant at 5 percent. This means that there is a negative and significant impact of miscellaneous factors on the productivity of the employees in Islamic banking industry. This negative influence further justifies that more attention is required for controlling the negative effects of factors on the productivity of the employees. Based on these findings, our study supports the argument that Productivity of the employees working in Islamic banking sector is significantly influenced by Miscellaneous factors (H-a). Through organizational culture, our study found no evidence for its significant impact on the productivity factor. However, coefficient of organizational culture is -0.084 and standard error of 0.082 . These results provide a critical ration of -1.02 , hence insignificant $\mathrm{p}$-value. It means that there is an insignificant impact of organizational culture on the productivity of Islamic banking employees.

For the factor of personal problem, coefficient is
-.915 which reflects a negative impact on the productivity of the employees. In addition, the critical ration of -12.88 is achieved through a standard error of 0.070. Finally, we achieved a significant level of 1 percent. It means that there is a significant and negative impact of personal problems on the productivity of the employees, providing the evidence that higher personal problems are leading towards lower level of employees' productivity and vice versa. Therefore, $\mathrm{H}-\mathrm{b}$ (Productivity of the employees working in Islamic banking sector is significantly influenced by personal problems) is supported in our study.

In addition, the factors of manager's attitude and job content show their positively insignificant impact on the productivity of the employees as p-values are found to be insignificant under full sample consideration. For the financial reward, coefficient is 0.119 which would indicate that higher financial reward is leading towards more productivity from the employees in Islamic banking sector. This result is justified through a standard error of 0.052 , and critical ration of 2.28 with the p-value of 0.038 . It means that there is a positive and significant impact of financial reward on the employees productivity, hence, H-f (Productivity of the employees working in Islamic banking sector is significantly influenced by financial reward) is supported. 


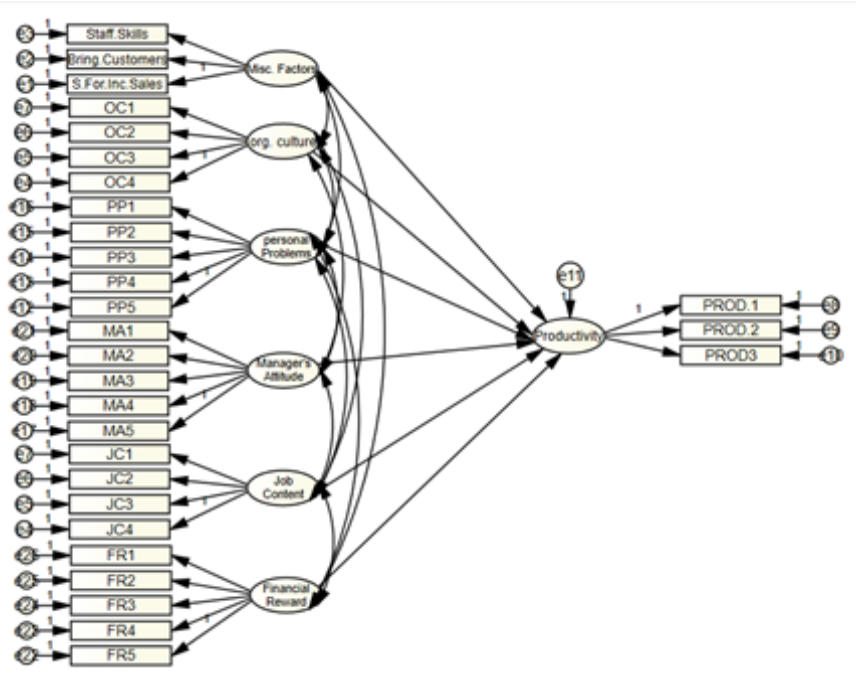

Figure 7. Structural model of the study.

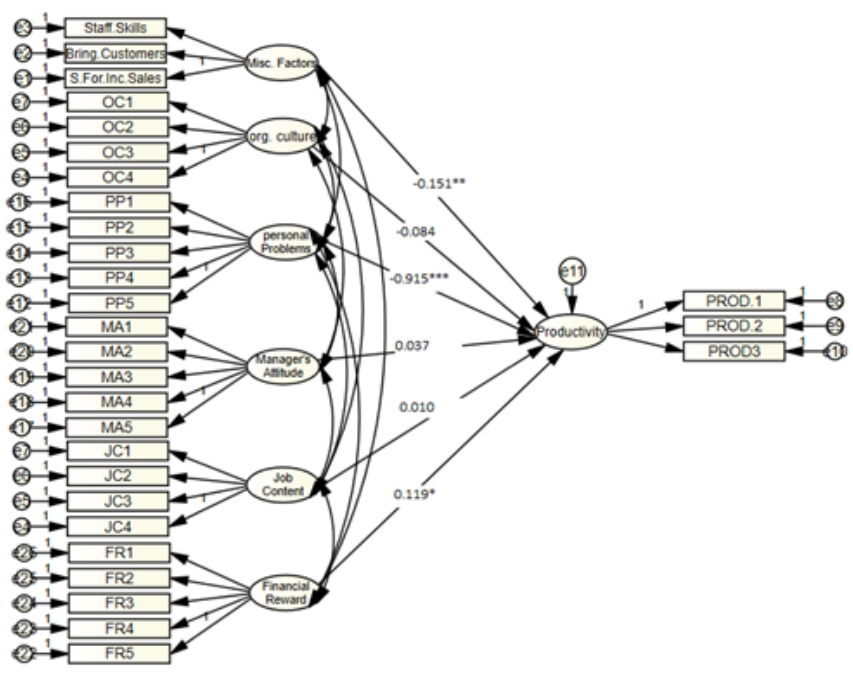

Figure 8. Output for the Structural Model with significant coefficients. 
Table 3. Findings for Structural Model: Factors Affecting the Employees Productivity in Islamic Banking

\begin{tabular}{|c|c|c|c|c|c|}
\hline Productivity & Reg. Coef & S.E & C.R & p-value & Sig. \\
\hline Miscellaneous Factors & -0.151 & 0.071 & -2.12 & 0.035 & $* *$ \\
\hline Organizational Culture & -0.084 & 0.082 & -1.02 & 0.342 & \\
\hline Personal Problems & -0.915 & 0.070 & -12.88 & 0.000 & $* * *$ \\
\hline Manager's Attitude & 0.037 & 0.810 & 0.045 & 0.603 & \\
\hline Job Content & 0.010 & 0.071 & 0.14 & 0.885 & \\
\hline Financial Reward & 0.119 & 0.052 & 2.28 & 0.038 & ** \\
\hline _cons & 3.522 & 0.758 & 4.64 & 0.000 & $* * *$ \\
\hline Mean dependent var & \multicolumn{2}{|c|}{4.507} & \multicolumn{2}{|c|}{ SD dependent var } & 0.501 \\
\hline R-squared & \multicolumn{2}{|c|}{0.251} & \multicolumn{2}{|c|}{ Number of observations } & 200 \\
\hline F-test & \multicolumn{2}{|c|}{8.2015} & \multicolumn{2}{|c|}{ Prob $>$ F } & 0.000 \\
\hline
\end{tabular}

\section{Conclusions}

All in all, the Islamic banking industry contributes hugely to community growth through funding customers' activities, thereby providing a balance between demand and supply of services offered. Islamic banking industry contributes significantly to developing the economy through the mobilization of savings and providing a cost-effective environment for money exchange. However, the Islamic banking industry has been experiencing various challenges, including the need for sales increase, convincing customers, developing staff's skills, and the development of competency among the staff. As a result, the research has provided recommendations for the above challenges and directives for further analysis. Need for Sales increase, bringing more customers, developing staff skills, and the need for competency among the staff are crucial aspects discussed in the research.

After reviewing the information provided by the
Islamic banking industry staff, it is evident that the Islamic banking industry is falling short of effective communication with the subordinate staff (Bose, 2018). Also, it lacks acceptable skills in the field of banking because it cannot accommodate the demands of the industry. The bank should review its policies on accommodation and rehabilitation of staff to ensure that core competencies are upheld while minding economic and humanitarian dimensions. The Islamic banking industry has been struggling with the issue of boosting its sales volume due to poor planning and making uninformed decisions. The staff does not have the necessary skills for marketing the products provided by the Islamic banks (Abdul-Majid et al., 2010). The banks will need to put in place interventions for boosting its administrative functions, marketing, sales, and operational strategies. These interventions will pave the way for winning more customers and creating a substantial competitive edge. 
In addition, the methodologies used limited research. The study encountered challenges from the interviewees. Some of the staff did not fill the questionnaires issued to them, thereby diminishing the reliability of research findings. Some of the techniques used, such as sampling, did not help in obtaining the opinions of staff attached to the remotely located branches. Also, most of the online interviews and questionnaires were not responded on time, which delayed the research findings. In the future, I would suggest the use of advanced tools that gather information from a larger population rather than focusing on samples. The existing research indicates that Islamic banking has been stable, yet it does not depend on low-income earners and small businesses. I would recommend for the examination of the strategies it has put in place to maintain stability. Notably, the Islamic banking industry has been facing challenges when it comes to raising the standards of services provided to be in line with the customer's demands. According to the underlying, staff in the Islamic banking industry does not have the capability of coping up with the ever-advancing level of technology (Ahmed, 2007). The bank's management should put more emphasis on employing only the potential candidates in addition to shaping their skills based on technological advancements. The research confirmed that the Islamic banking industry has been facing challenges in attracting customers to the banks. Hassan and Aliyu (2018) suggest that the primary cause of this issue is poor marketing strategies, which cannot induce a potential customer to have confidence in the services provided. Besides, the Islamic banking industry can boost its service provision through sales promotion, engaging with customers at a personal level, and offering other services not provided in other conventional banks.

\section{References}

Abdul-Majid, M., Saal, D. S., \& Battisti, G. (2010). Efficiency in Islamic and conventional banking: an international comparison. Journal of productivity analysis, $34(1), 25-43$.

Ahmed, G. A. (2007). Participatory finance in Sudanese banking system: Perceptions on performance, obstacles and prospects. Durham University.

Azmat, S., Azad, A., Ghaffar, H., \& Bhatti, I. (2015). Why interest free Islamic banking is not free from interest? Working Paper, Deakin University. https://www. deakin.edu. au/_data/assets/pdf_file/0003/392295/ islamic-banking-notfree-from-interest-Azmat-AzadGhaffar-and-Bhatti.pdf (accessed on Oct. 22, 2017).

Bose, I. (2018a). Employee empowerment and employee performance: An empirical study on selected banks in UAE. Journal of Applied Management and Investments, 7(2), 71-78.

Bose, I. (2018b). The strategic environment of the aviation industry in UAE: A case study on Etihad Airways. IIUM Journal of Case Studies in Management, 9(1), 21-27.

Gerrard, P., \& Cunningham, J. B. (1997). Islamic banking: a study in Singapore. The International Journal of Bank Marketing, 15(6), 204-216.

Hassan, M. K., \& Aliyu, S. (2018). A contemporary survey of Islamic banking literature. Journal of Financial Stability, 34, 12-43.

Hussain, H. I., Kamarudin, F., Mohamad Anwar, N. A., Nassir, A. M., Sufian, F., Mang Tan, K. (2020), Impact of country's governance dimensions on bank revenue efficiency: Overview on Middle East, Southeast Asia, and South Asia countries, Transformations in Business \& Economics, 19(1), 191-228.

Jan, M. T. (2018). Will it survive? Challenges faced by Islamic banking and finance in today's World. Journal of Islamic Finance, 176(6217), 1-10.

Kumar, V., Smart, P., Maddern, H., \& Maull, R. (2008). Alternative perspectives on service quality and customer satisfaction: the role of BPM. International Journal of Service Industry Management, 19(2), 176-187.

Maghyereh, A. I. (2018). Bank competition, concentration and risk-taking in the UAE banking industry. Economia Internazionale/International Economics, 71(2), 129-148.

Okumus, H. (2005). Interest-free banking in Turkey: a study of customer satisfaction and bank selection criteria. Journal of Economic Cooperation, 26(4), 51-86.

Peppard, J. (2000). Customer relationship management (CRM) in financial services. European Management Journal, 18(3), 312-327.

Saeed, A. (1996). Islamic banking and interest: A study of the prohibition of riba and its contemporary interpretation (Vol. 2): Brill.

Tiwari, R., Buse, S., \& Herstatt, C. (2006). Mobile banking as business strategy: Impact of mobile technologies on customer behaviour and its implications for banks. Paper presented at the 2006 Technology Management for the Global Future-PICMET 2006 Conference. 